\title{
Bridge Resonance Effects in Singlet Fission
}

Kaia R. Parenti ${ }^{1}$, Guiying He ${ }^{2,3}$, Samuel N. Sanders ${ }^{1}$, Andrew B. Pun ${ }^{1}$, Elango Kumarasamy ${ }^{1}$, Matthew Y.Sfeir ${ }^{2,3^{*}}$, and Luis M. Campos ${ }^{1 *}$

${ }^{1}$ Department of Chemistry, Columbia University, New York, New York 10027, United States

${ }^{2}$ Department of Physics, Graduate Center, City University of New York, New York, NY 10016, USA

${ }^{3}$ Photonics Initiative, Advanced Science Research Center, City University of New York, New York, NY 10031, USA 
Table of Contents

I. General Methods

II. Frontier Orbital Energies

III. Transient Absorption Spectroscopy

IV. Triplet Sensitization

V. Spectral Decomposition

VI. Triplet Pair Recombination of Pentacene Series

VII. Singlet Fission Yield Determination

VIII. UV-Vis Absorption Spectra

IX. Synthetic Procedures

$X$. NMR Spectra

XI. References 


\section{General Methods}

All commercially obtained reagents were used as received; chemicals were purchased from Alfa Aesar ${ }^{\circledR}$, Sigma-Aldrich ${ }^{\circledR}$, Acros Organics $^{\circledR}$, TCl America ${ }^{\circledR}$, Mallinckrodt ${ }^{\circledR}$, and Oakwood ${ }^{\circledR}$ Products, and were used as received without further purification. Anhydrous solvents were obtained from a Schlenk manifold with purification columns packed with activated alumina and supported copper catalyst (Glass Contour, Irvine, CA). Unless stated otherwise, reactions were conducted in oven-dried glassware under argon atmosphere. BPin TIPS Pentacene, Br TIPS Pentacene, BPin TIPS Tetracene, 1B, 2, BP1, BP2, BT1, and BT2 were synthesized according to literature procedures. $^{1-4}$

${ }^{1} \mathrm{H}-\mathrm{NMR}$ and ${ }^{13} \mathrm{C}-\mathrm{NMR}$ spectra were recorded on Bruker $400 \mathrm{MHz}(100 \mathrm{MHz}$ for ${ }^{13} \mathrm{C}$ ) and on $500 \mathrm{MHz}\left(125 \mathrm{MHz}\right.$ for $\left.{ }^{13} \mathrm{C}\right)$ spectrometers. Data from the ${ }^{1} \mathrm{H}-\mathrm{NMR}$ and ${ }^{13} \mathrm{C}-$ NMR spectroscopy are reported as chemical shift ( $\delta \mathrm{ppm})$ with the corresponding integration values. Coupling constants $(J)$ are reported in hertz $(\mathrm{Hz})$. Standard abbreviations indicating multiplicity were used as follows: s (singlet), d (doublet), $t$ (triplet), q (quartet), and m (multiplet).

The mass spectral data for the compounds were obtained from XEVO G2-XS Waters ${ }^{\circledR}$ equipped with a QTOF detector with multiple inlet and ionization capabilities including electrospray ionization (ESI), atmospheric pressure chemical ionization (APCI), and atmospheric solids analysis probe (ASAP). The base peaks were usually obtained as $[\mathrm{M}]^{+}$or $[\mathrm{M}+\mathrm{H}]^{+}$ions.

Absorption spectra were obtained on a Shimadzu UV 1800 UV-Vis spectrophotometer. 


\section{Frontier Orbital Energies}

Experimental orbital energies for the compounds studied here were obtained from literature values according to established protocol ${ }^{5}$ and are summarized in Table S1. Specifically, the HOMO energy reported as the negative of the oxidation potential while the LUMO energy is the difference between the lowest singlet excited state energy and the oxidation potential. DFT calculations were performed using Q-Chem 5.0. at the B3LYP/6-311G** level of theory (Table S2).

Table S1. Experimental HOMO and LUMO values (eV, relative to vacuum) of the compounds studied in this work.

\begin{tabular}{|c|c|c|}
\hline Compound & HOMO $(\mathbf{e V})$ & LUMO $(\mathbf{e V})$ \\
\hline Benzene $^{6,7}$ & -7.2 & -2.3 \\
\hline Biphenyl $^{7,8}$ & -6.6 & -2.3 \\
\hline Naphthalene $^{8,9}$ & -6.5 & -2.5 \\
\hline Benzodithiophene $^{10}$ & -5.8 & -2.6 \\
\hline TIPS Anthracene $^{11,12}$ & -5.6 & -2.9 \\
\hline TIPS Tetracene $^{11,12}$ & -5.4 & -3.2 \\
\hline TIPS Pentacene $^{11,12}$ & -5.2 & -3.3 \\
\hline
\end{tabular}

Table S2. Calculated HOMO and LUMO values (eV, relative to vacuum) of the compounds studied in this work.

\begin{tabular}{|c|c|c|}
\hline Compound & HOMO $(\mathbf{e V})$ & LUMO $(\mathbf{e V})$ \\
\hline Benzene & -7.0 & -0.2 \\
\hline Biphenyl & -6.3 & -0.9 \\
\hline Naphthalene & -6.0 & -1.3 \\
\hline Benzodithiophene & -5.4 & -1.3 \\
\hline TIPS Anthracene & -5.4 & -2.5 \\
\hline TIPS Tetracene & -5.1 & -2.7 \\
\hline TIPS Pentacene & -4.9 & -3.0 \\
\hline
\end{tabular}




\section{Transient Absorption Spectroscopy}

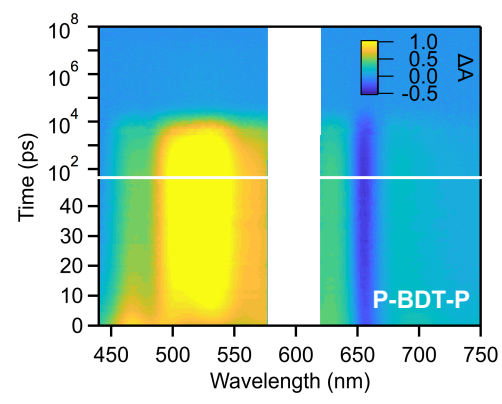

Figure S1. Raw femtosecond and nanosecond data of P-BDT-P in dilute chloroform solution excited at $600 \mathrm{~nm}$. Raw femtosecond and nanosecond data of BP2 has been previously reported. ${ }^{1}$
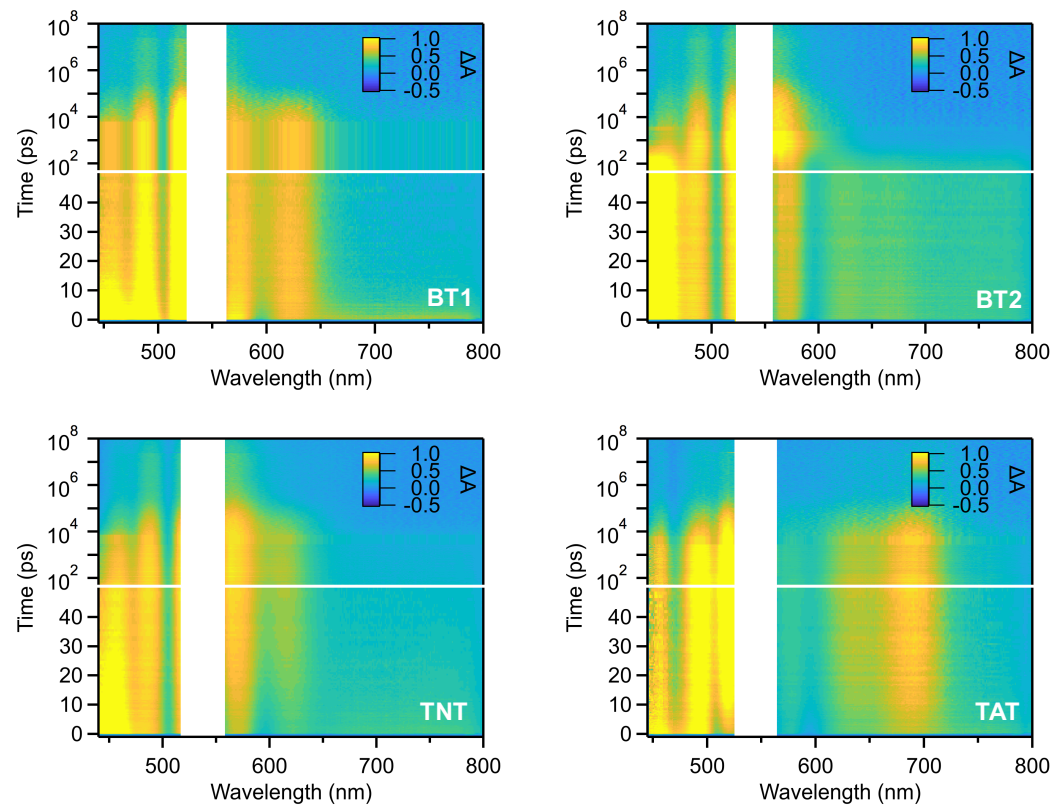

Figure S2. Raw femtosecond and nanosecond data of BT1, BT2, TNT, and TAT in dilute toluene solution excited at $545 \mathrm{~nm}$. 


\section{Triplet Sensitization}
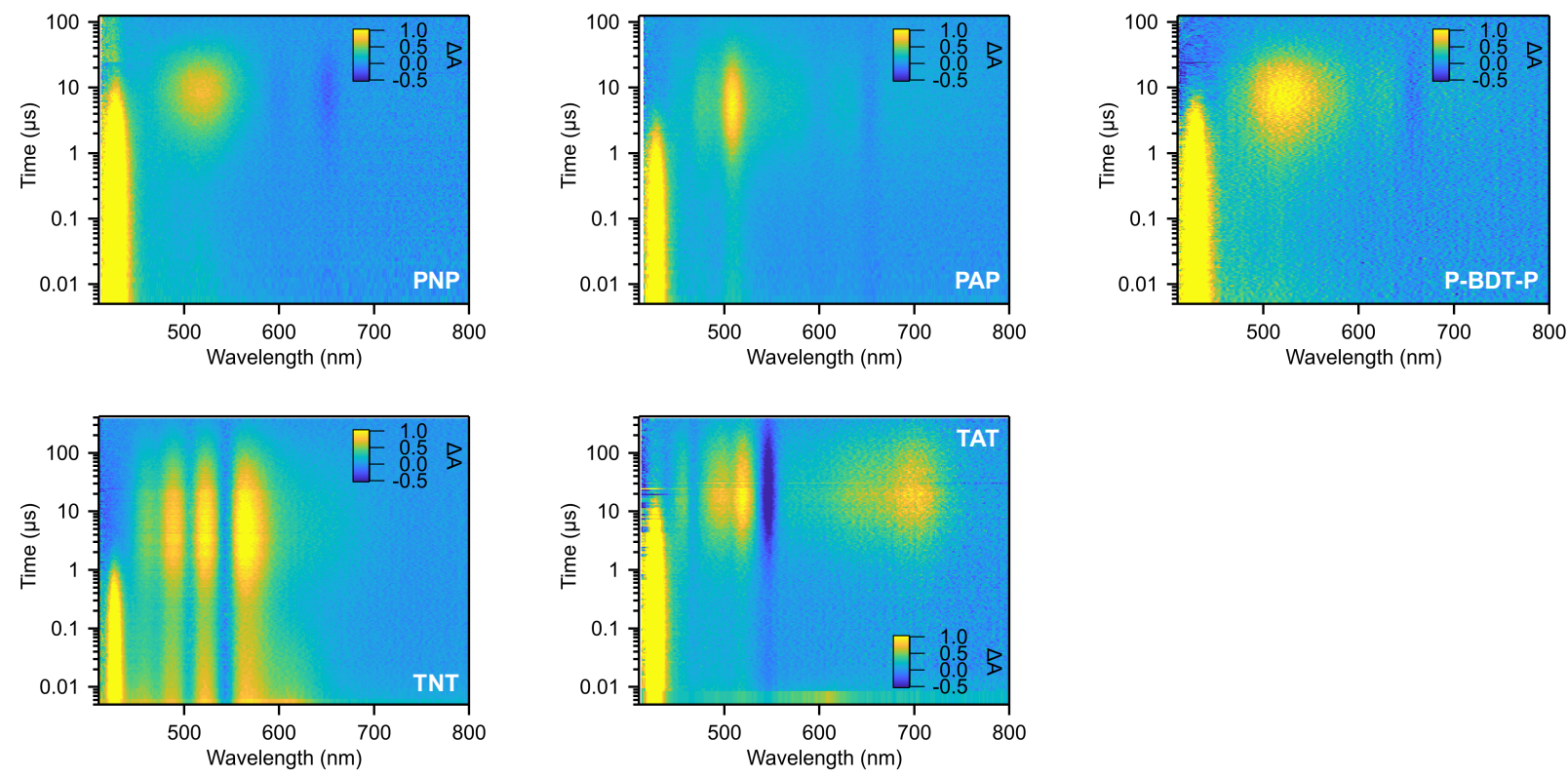

Figure S3. Triplet photosensitization measurements of PNP, PAP, P-BDT-P, TNT, and TAT and $\sim 20 \mathrm{mM}$ anthracene dissolved in chloroform, with excitation at $360 \mathrm{~nm}$ $(\sim 100 \mu \mathrm{J} / \mathrm{cm} 2)$ to preferentially excite anthracene molecules. Triplet photosensitization of BT1, BT2, BP1, and BP2 have been previously reported. ${ }^{1,2}$ 


\section{Spectral Decomposition}

BT1
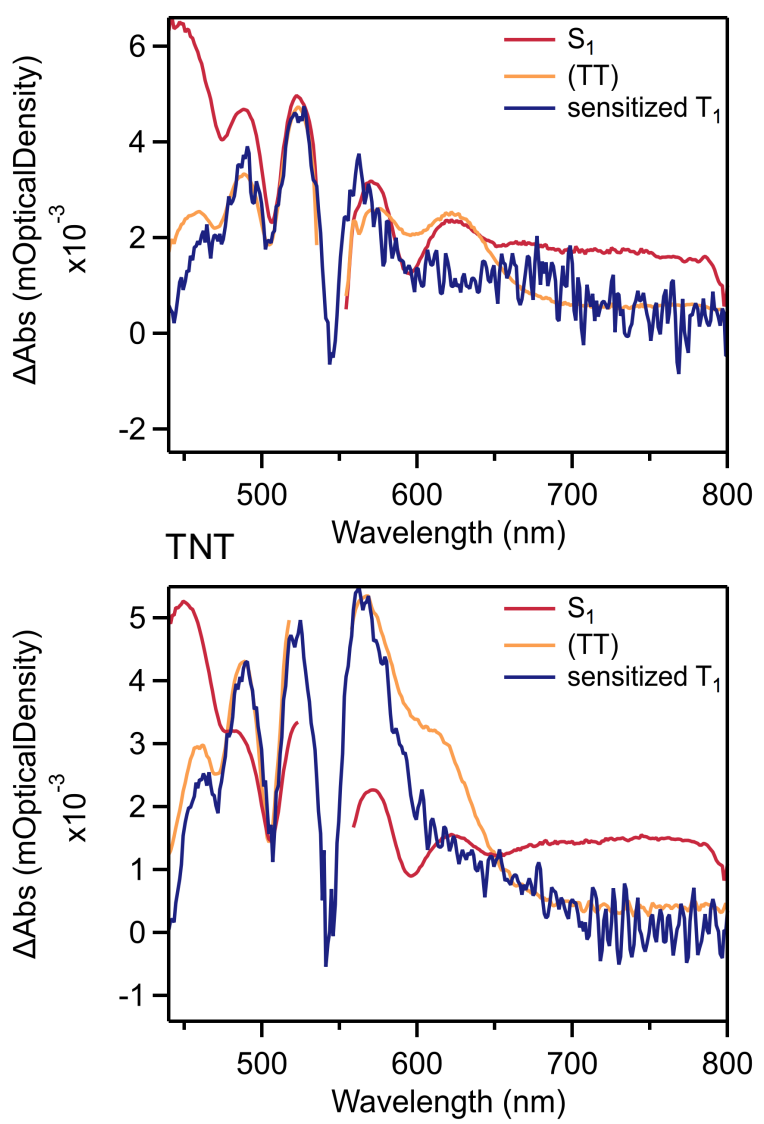

BT2
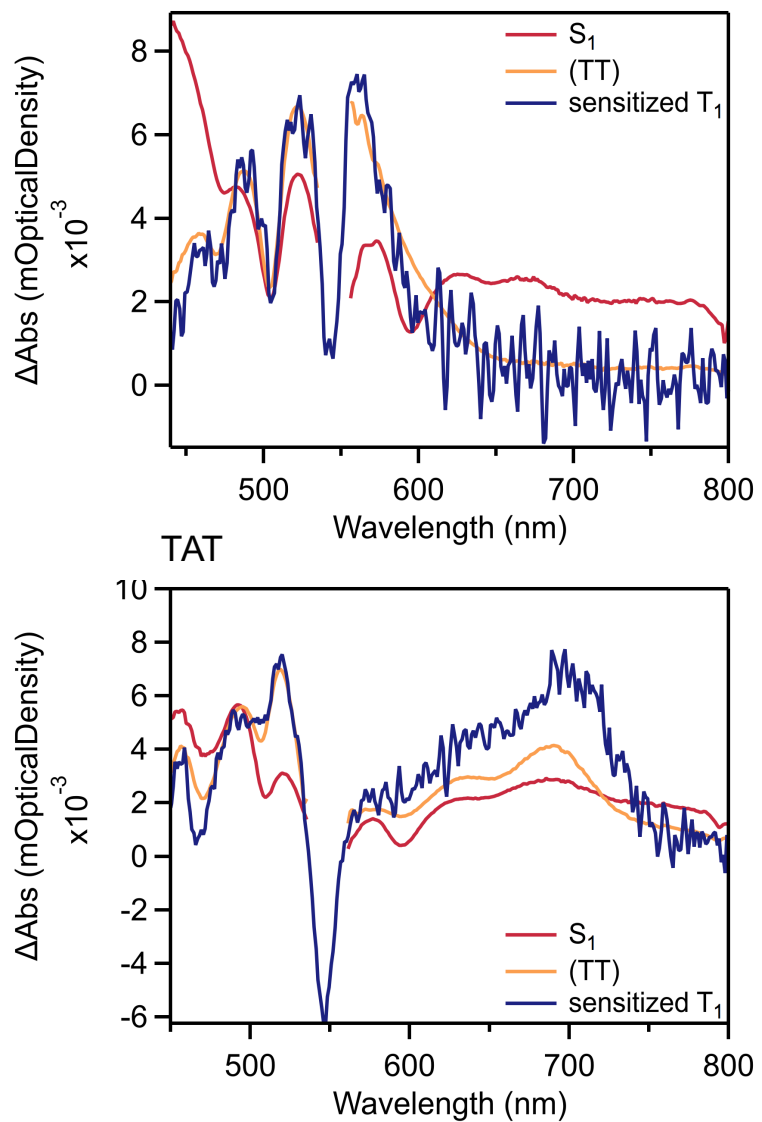

Figure S4. Singlet and triplet pair spectra isolated from global analysis of transient absorption data in dilute toluene solution of BT1, BT2, TNT, and TAT. Sensitized $T_{1}$ traces from triplet photosensitization experiments are overlaid. 


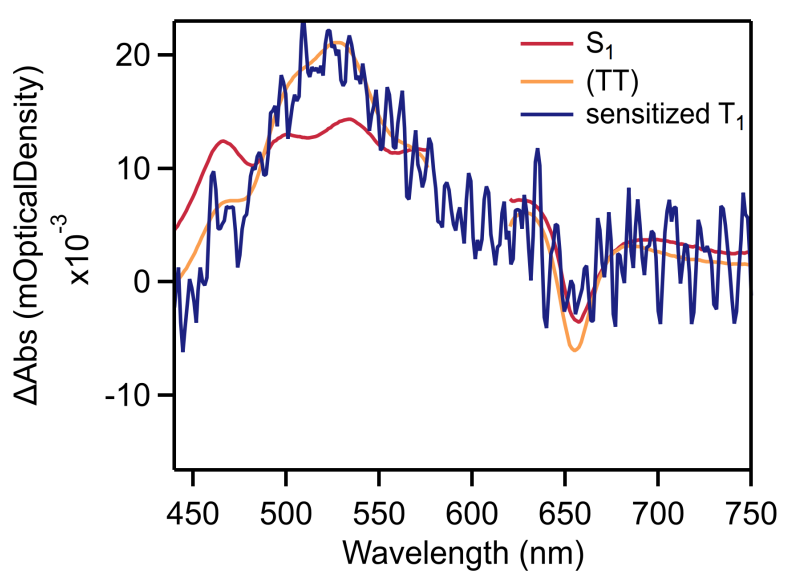

Figure S5. Singlet and triplet pair spectra isolated from global analysis of transient absorption data in dilute chloroform solution of P-BDT-P. A sensitized $T_{1}$ trace from triplet photosensitization experiments is overlaid. Global analysis of BP2 has been previously reported. ${ }^{1}$ 


\section{Triplet Pair Recombination of Pentacene Series}

Table S3. Time constants for singlet fission and triplet pair decay in the pentacene series.

\begin{tabular}{|c|c|c|c|}
\hline Compound & $\boldsymbol{\tau}_{\mathrm{SF}}(\mathrm{ps})$ & $\boldsymbol{\tau}_{1(\mathrm{TT})}(\mathrm{ns})$ & $\boldsymbol{\tau}_{\mathrm{T} 1}(\mu \mathrm{s})$ \\
\hline BP1 & 20 & 16.5 & 30 \\
\hline BP2 & 220 & 270 & 20 \\
\hline PNP & 46 & 50 & 20 \\
\hline PAP & 43 & 79 & 17 \\
\hline P-BDT-P & 13 & 14 & 10 \\
\hline
\end{tabular}

The materials in the pentacene series exhibit biexponential recombination dynamics, with a dominant short lifetime component and a minor long lifetime component. These recombination dynamics align with our previous reports of similar bridged pentacene dimers. ${ }^{1,13}$ We assign the dominant short lifetime component to the net singlet triplet pair ${ }^{1}$ (TT) that has been shown to undergo a direct radiationless decay to the ground state in competition with dephasing. We assign the long lifetime component to a small population of free triplets, $T_{1}$, that form following dephasing of the triplet pair. 


\section{Singlet Fission Yield Determination}

We observe an isosbestic point between the singlet and triplet pair species in PNP, PAP, P-BDT-P, BT1, TNT, TAT, and BT2. This is indicative of quantitative SF yields with no population losses or formation of parasitic species. ${ }^{14,15}$ The kinetic traces at these points are flat in time over the timescales of SF.
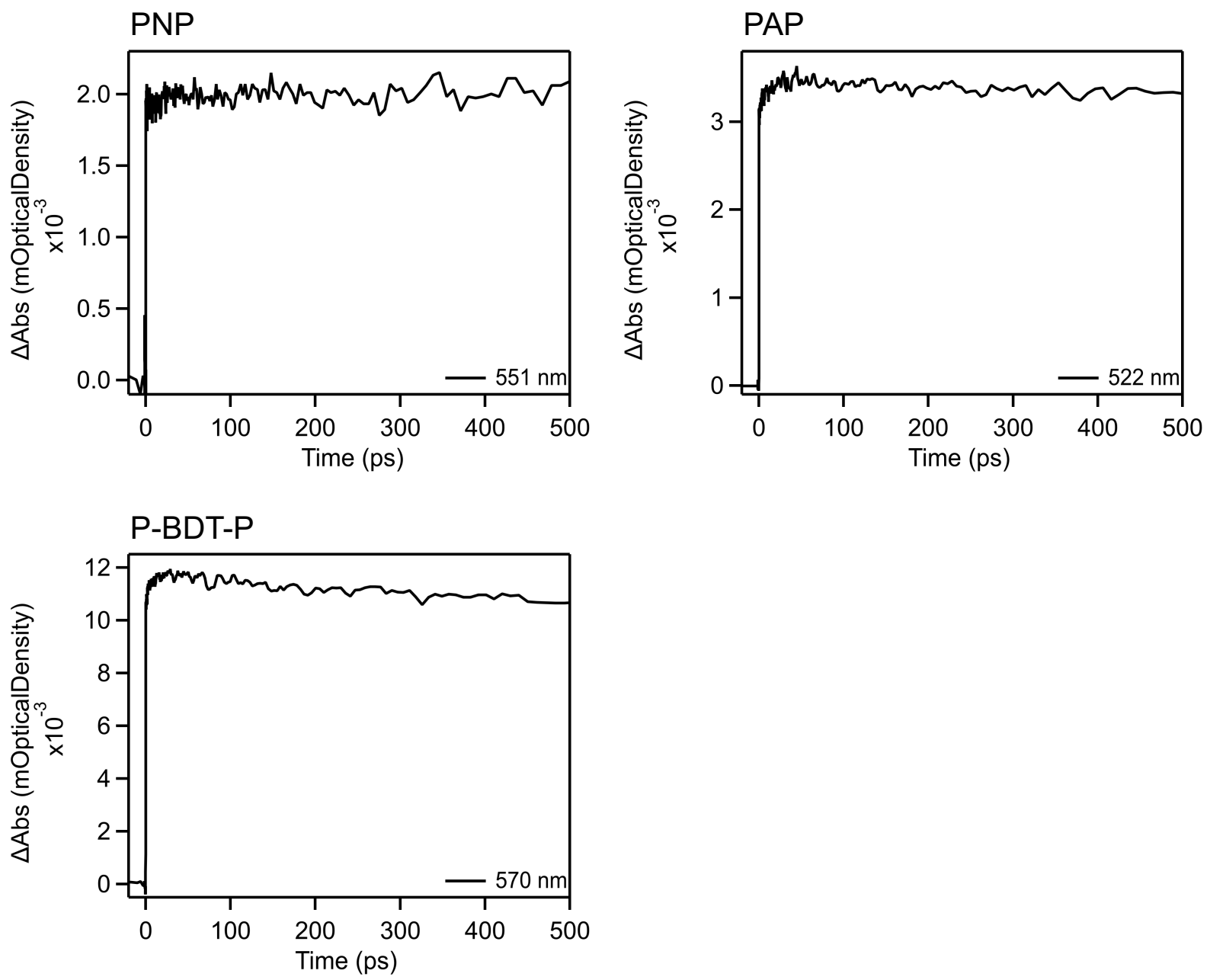

Figure S6. Kinetic traces at wavelengths corresponding to isosbestic points in PNP, PAP, and P-BDT-P from fsTA. 

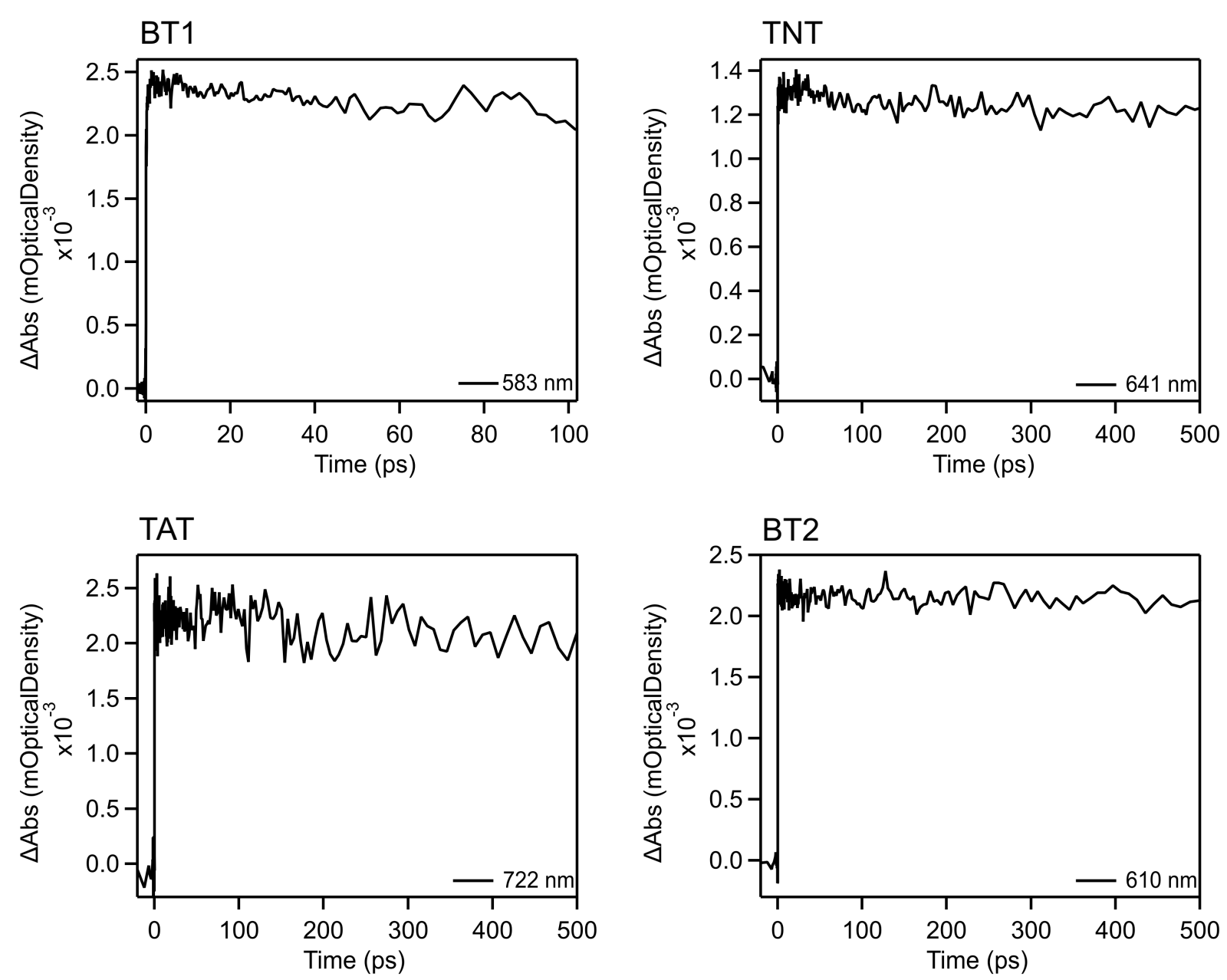

Figure S7. Kinetic traces at wavelengths corresponding to isosbestic points in BT1, TNT, TAT, and BT2 from fsTA. 


\section{UV-Vis Absorption Spectra}

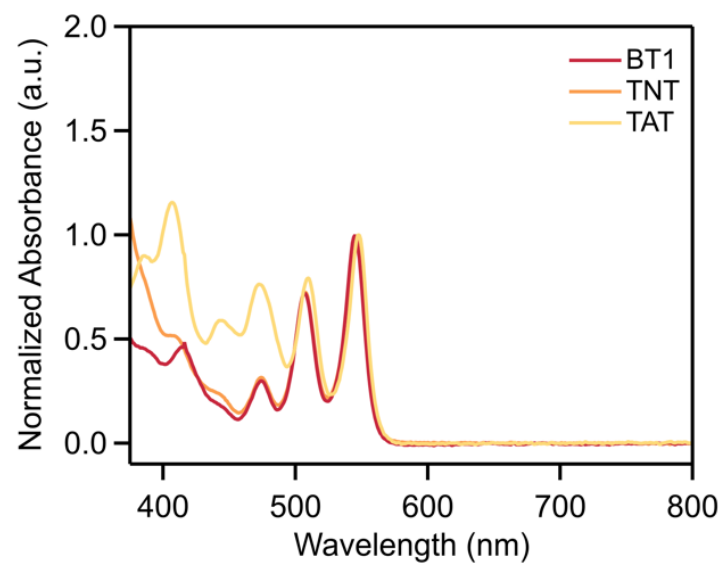

Figure S8. Normalized steady-state absorption spectra of BT1, TNT, and TAT in dilute toluene solution. 


\section{Synthetic Procedures}

\section{General Procedure A}

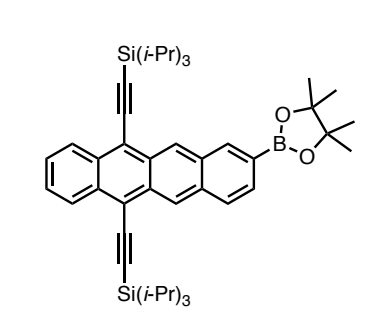<smiles>Brc1ccc2cc(Br)ccc2c1</smiles>

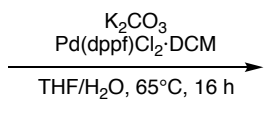

BPin TIPS Tetracene

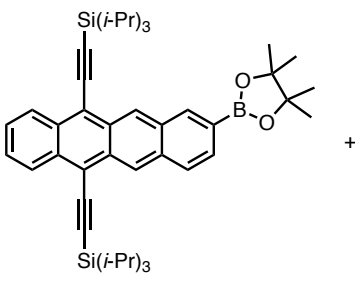

BPin TIPS Tetracene

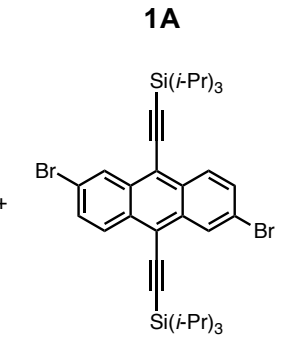

1B
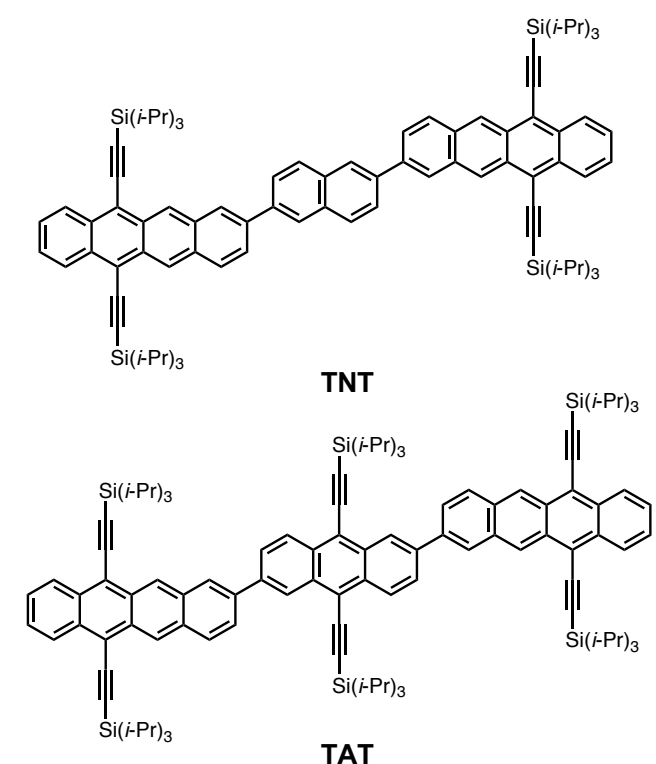

BPin TIPS Tetracene (2.2 equiv.), $1 \mathrm{~A}$ or $1 \mathrm{~B}$ (1.0 equiv.), $\mathrm{K}_{2} \mathrm{CO}_{3}$ (10.0 equiv.), and $\mathrm{Pd}(\mathrm{dppf}) \mathrm{Cl}_{2} \cdot \mathrm{DCM}$ (0.1 equiv.) were added to a reaction vial. Sequential vacuum and argon were used to degas the mixture. The solids were then dissolved in a 9:1 mixture $(0.015 \mathrm{M})$ of dry THF: degassed water. The reaction was brought to $65^{\circ} \mathrm{C}$ and stirred for 16 hours. The reaction was cooled to room temperature, dried over anhydrous $\mathrm{Na}_{2} \mathrm{SO}_{4}$, filtered, and concentrated down. The crude was purified by column chromatography on silica gel using hexanes/chloroform as the eluent to yield TNT or TAT. 


\section{Synthesis and Characterization of TNT and TAT}

TNT

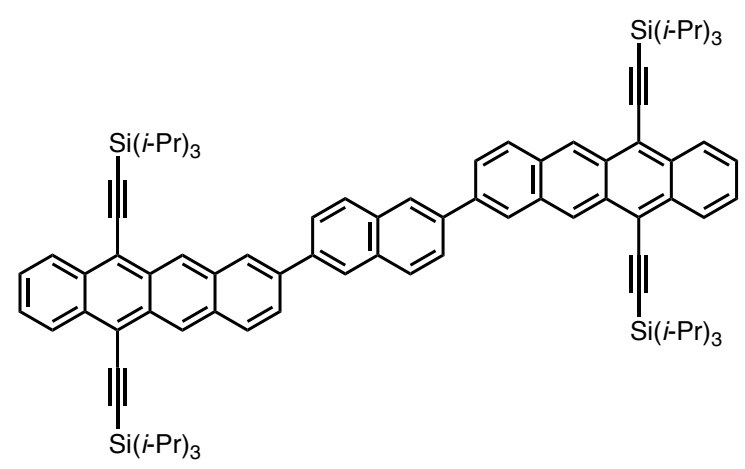

Prepared according to General Procedure A (0.095 mmol scale).

Yield: $60 \%$; red solid

${ }^{1} \mathrm{H}-\mathrm{NMR}\left(400 \mathrm{MHz} \mathrm{CDCl}_{3}, \delta \mathrm{ppm}\right): 9.38$ (d, 4H), $8.65(\mathrm{~m}, 4 \mathrm{H}), 8.33(\mathrm{~d}, 4 \mathrm{H}), 8.16$

$(\mathrm{t}, 4 \mathrm{H}), 8.03(\mathrm{~d}, 2 \mathrm{H}), 7.95(\mathrm{~d}, 2 \mathrm{H}), 7.60-7.54(\mathrm{~m}, 4 \mathrm{H}), 1.40-1.32(\mathrm{~m}, 84 \mathrm{H})$

Limited solubility of material prevented the acquisition of a ${ }^{13} \mathrm{C}-\mathrm{NMR}$.

MS (APCI): Calculated: 1301.7606; Observed: 1301.7592

\section{TAT}

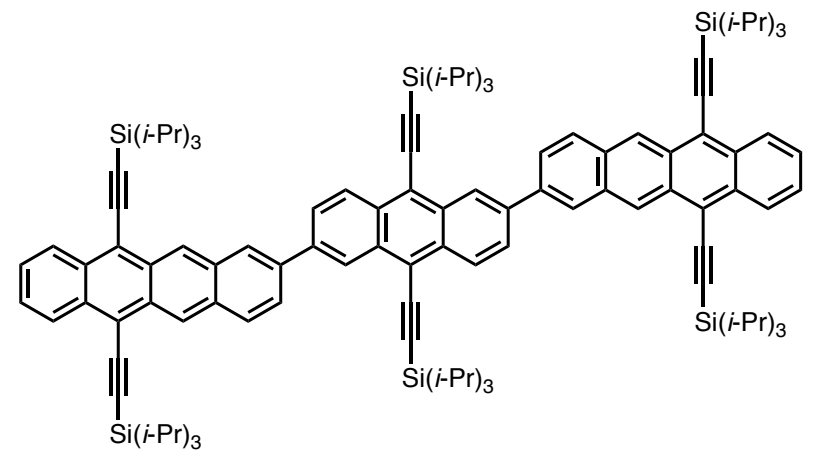

Prepared according to General Procedure A (0.13 mmol scale).

Yield: 45\%; red/orange solid

${ }^{1} \mathrm{H}-\mathrm{NMR}$ (400 MHz, $\mathrm{CDCl}_{3}, \delta$ ppm): 9.38 (d, 4H), 9.09 (d, 2H), 8.82 (d, 2H), 8.66 (m, 4H), $8.38(\mathrm{~s}, 2 \mathrm{H}), 8.17-8.10(\mathrm{~m}, 4 \mathrm{H}), 7.98(\mathrm{~d}, 2 \mathrm{H}), 7.59-7.55(\mathrm{~m}, 4 \mathrm{H}), 1.39$ $-1.31(\mathrm{~m}, 127 \mathrm{H})$

Limited solubility of material prevented the acquisition of a ${ }^{13} \mathrm{C}-\mathrm{NMR}$.

MS (APCI): Calculated: 1712.0431; Observed: 1712.0442 


\section{General Procedure B}

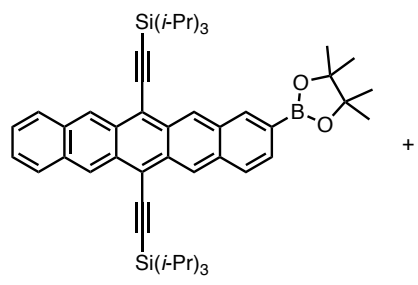

BPin TIPS Pentacene<smiles>Brc1ccc2cc(Br)ccc2c1</smiles>

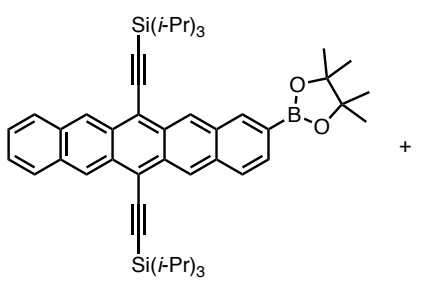

BPin TIPS Pentacene
$1 \mathrm{~A}$

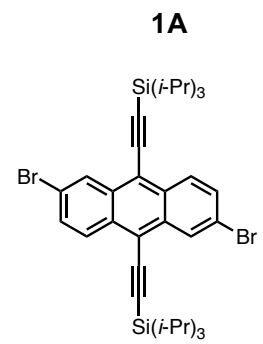

$1 B$
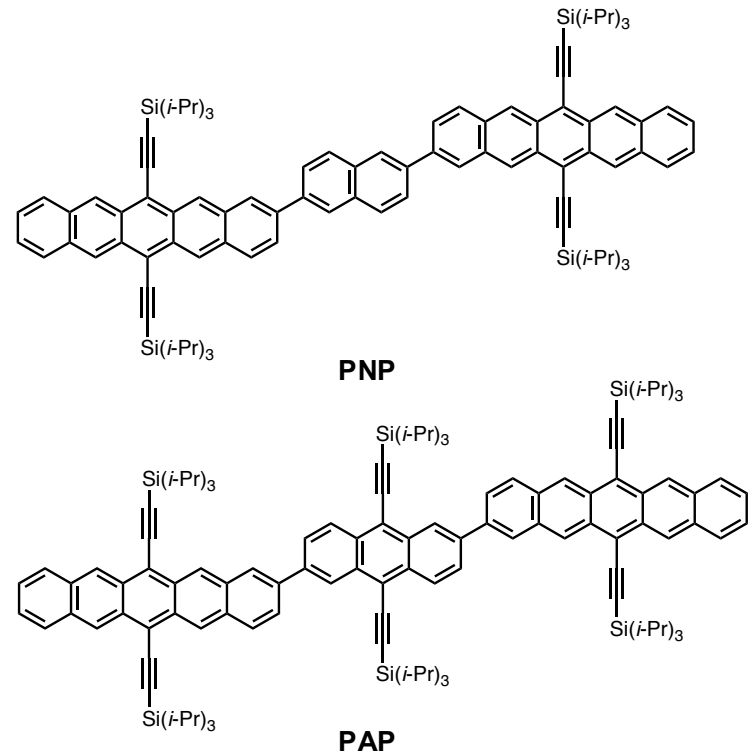

BPin TIPS Pentacene (2.2 equiv.), 1A or 1B (1.0 equiv.), $\mathrm{K}_{2} \mathrm{CO}_{3}(10.0$ equiv.), and $\mathrm{Pd}(\mathrm{dppf}) \mathrm{Cl}_{2} \cdot \mathrm{DCM}$ (0.1 equiv.) were added to a reaction vial. Sequential vacuum and argon were used to degas the mixture. The solids were then dissolved in a 9:1 mixture $(0.015 \mathrm{M})$ of dry THF: degassed water. The reaction was brought to $65^{\circ} \mathrm{C}$ and stirred for 16 hours. The reaction was cooled to room temperature, dried over anhydrous $\mathrm{Na}_{2} \mathrm{SO}_{4}$, filtered, and concentrated down. The crude was purified by column chromatography on silica gel using hexanes/chloroform as the eluent to yield PNP or PAP. 


\section{Synthesis and Characterization of PNP and PAP}

PNP

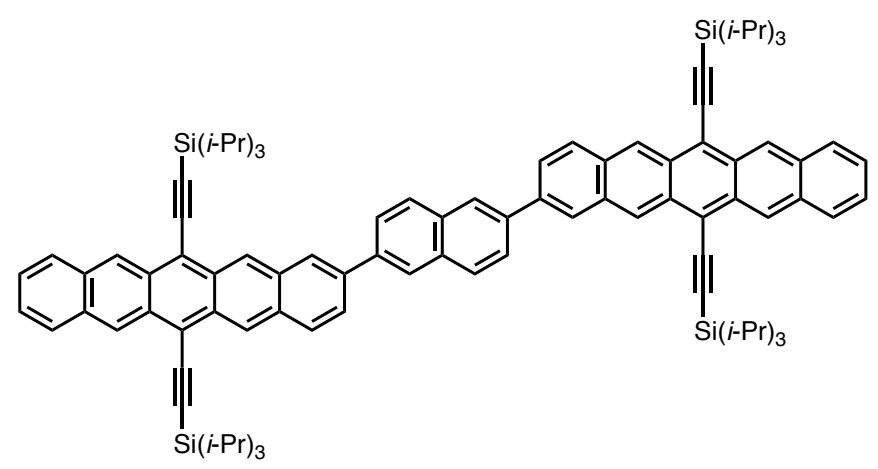

Prepared according to General Procedure B (0.17 mmol scale).

Yield: 71\%; blue/green solid

${ }^{1} \mathrm{H}-\mathrm{NMR}\left(400 \mathrm{MHz}, \mathrm{CDCl}_{3}, \delta \mathrm{ppm}\right): 9.43-9.27(\mathrm{~m}, 8 \mathrm{H}), 8.31(\mathrm{~s}, 4 \mathrm{H}), 8.14(\mathrm{t}$, $4 \mathrm{H}), 8.05-7.97(\mathrm{~m}, 6 \mathrm{H}), 7.90(\mathrm{~d}, 2 \mathrm{H}), 7.42(\mathrm{~m}, 4 \mathrm{H}), 1.47-1.38(\mathrm{~m}, 85 \mathrm{H})$ Limited solubility of material prevented the acquisition of a ${ }^{13} \mathrm{C}-\mathrm{NMR}$. MS (ESI): Calculated: 1401.7869; Observed: 1401.7860

\section{PAP}

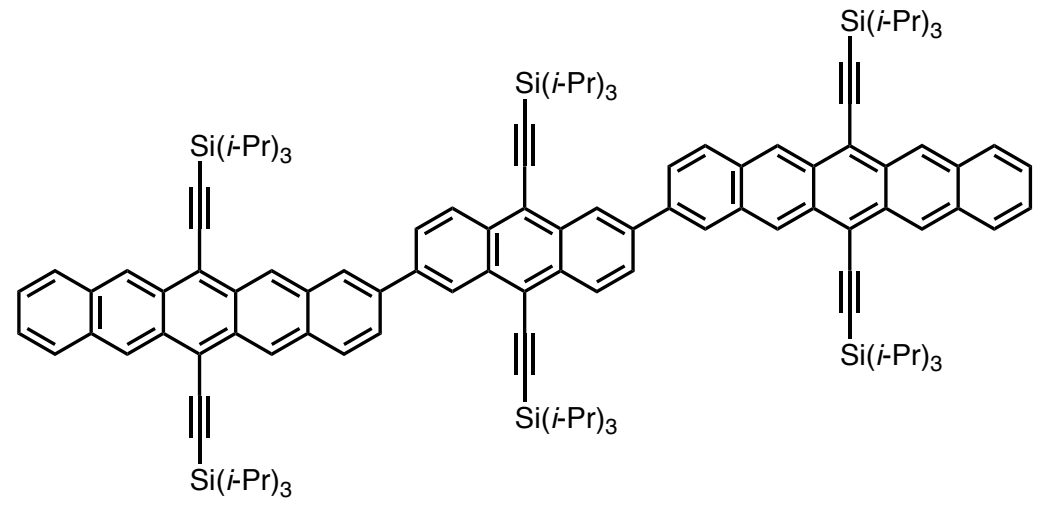

Prepared according to General Procedure B (0.07 mmol scale).

Yield: 25\%; green solid

${ }^{1} \mathrm{H}-\mathrm{NMR}\left(400 \mathrm{MHz}, \mathrm{CDCl}_{3}, \delta \mathrm{ppm}\right): 9.41-9.31(\mathrm{~m}, 8 \mathrm{H}), 9.10(\mathrm{~m}, 2 \mathrm{H}), 8.83(\mathrm{~d}$, $2 \mathrm{H}), 8.35(\mathrm{~s}, 2 \mathrm{H}), 8.16-8.08(\mathrm{~m}, 4 \mathrm{H}), 8.01-7.91(\mathrm{~m}, 6 \mathrm{H}), 7.43(\mathrm{~d}, 4 \mathrm{H}), 1.45-$ $1.38(\mathrm{~m}, 84 \mathrm{H}), 1.37-1.31(\mathrm{~m}, 42 \mathrm{H})$ Limited solubility of material prevented the acquisition of a ${ }^{13} \mathrm{C}-\mathrm{NMR}$. 
MS (ESI): Calculated: 1812.0744; Observed: 1812.0746

\section{Synthesis and Characterization of P-BDT-P}
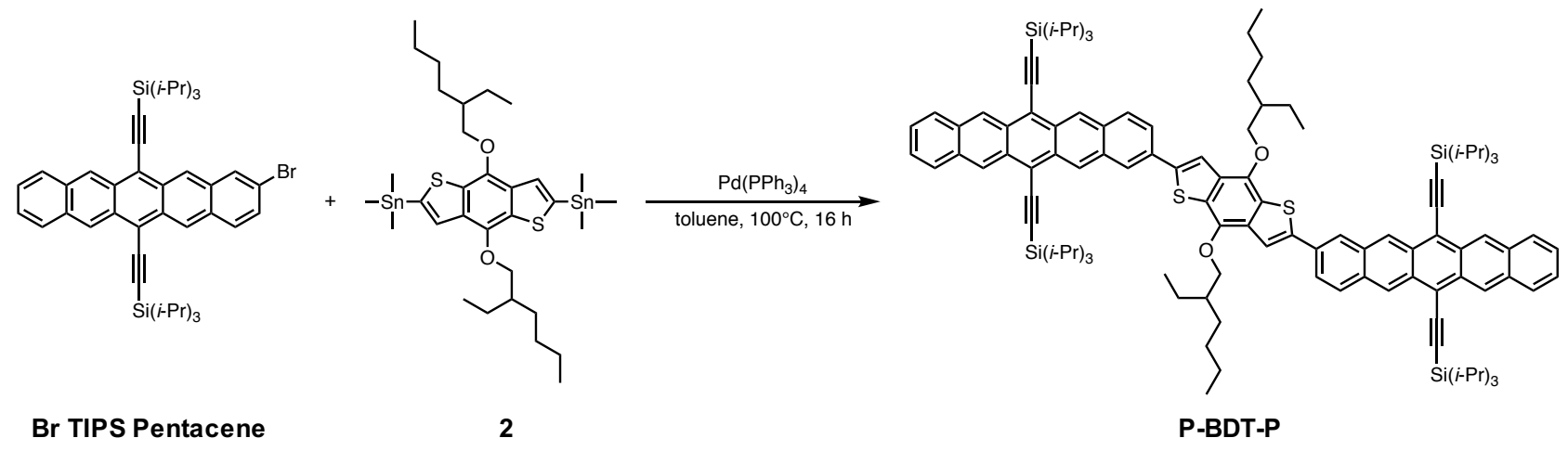

Br TIPS Pentacene (2.2 equiv.), 2 (1.0 equiv., $0.11 \mathrm{mmol})$, and $\mathrm{Pd}\left(\mathrm{Ph}_{3}\right)_{4}(0.1$ equiv.) were added to a reaction vial. Sequential vacuum and argon were used to degas the mixture. The solids were then dissolved in dry toluene $(0.01 \mathrm{M})$. The reaction was brought to $100^{\circ} \mathrm{C}$ and stirred for 16 hours. The reaction was cooled to room temperature, filtered through a bed of silica, and concentrated down. The crude was purified by column chromatography on silica gel using hexanes/chloroform as the eluent to yield P-BDT-P.

Yield: 82\%; blue/green solid

${ }^{1} \mathrm{H}-\mathrm{NMR}\left(400 \mathrm{MHz}, \mathrm{CDCl}_{3}, \delta \mathrm{ppm}\right): 9.36-9.28(\mathrm{~m}, 8 \mathrm{H}), 8.26(\mathrm{~s}, 2 \mathrm{H}), 8.04$ (d, 2H), $7.98(\mathrm{q}, 4 \mathrm{H}), 7.89(\mathrm{~s}, 2 \mathrm{H}), 7.85(\mathrm{~d}, 2 \mathrm{H}), 7.45-7.40(\mathrm{~m}, 4 \mathrm{H}), 4.37$ - $4.31(\mathrm{~m}$, $4 \mathrm{H}), 1.97(\mathrm{~m}, 2 \mathrm{H}), 1.86(\mathrm{~m}, 2 \mathrm{H}), 1.73(\mathrm{~m}, 4 \mathrm{H}), 1.63(\mathrm{~m}, 2 \mathrm{H}), 1.50(\mathrm{~m}, 10 \mathrm{H}), 1.41$ $(\mathrm{m}, 84 \mathrm{H}), 1.17(\mathrm{t}, 6 \mathrm{H}), 1.02(\mathrm{t}, 6 \mathrm{H})$

${ }^{13} \mathrm{C}-\mathrm{NMR}:\left(125 \mathrm{MHz}, \mathrm{CDCl}_{3}, \delta \mathrm{ppm}\right): 144.28,143.22,132.90,132.22,132.18$, $131.85,131.36,131.23,130.94,130.77,130.60,130.53,129.29,129.25,128.51$, $126.69,126.22,126.20,126.12,125.95,125.90,125.31,124.26,118.36,118.26$, $116.58,107.26,106.99,104.57,104.49,75.93,40.60,30.45,29.22,23.85$, $23.15,18.96,18.94,14.19,11.65,11.61,11.37$ MS (ESI): Calculated: 1718.9528; Observed: 1718.9525 


\section{NMR Spectra}

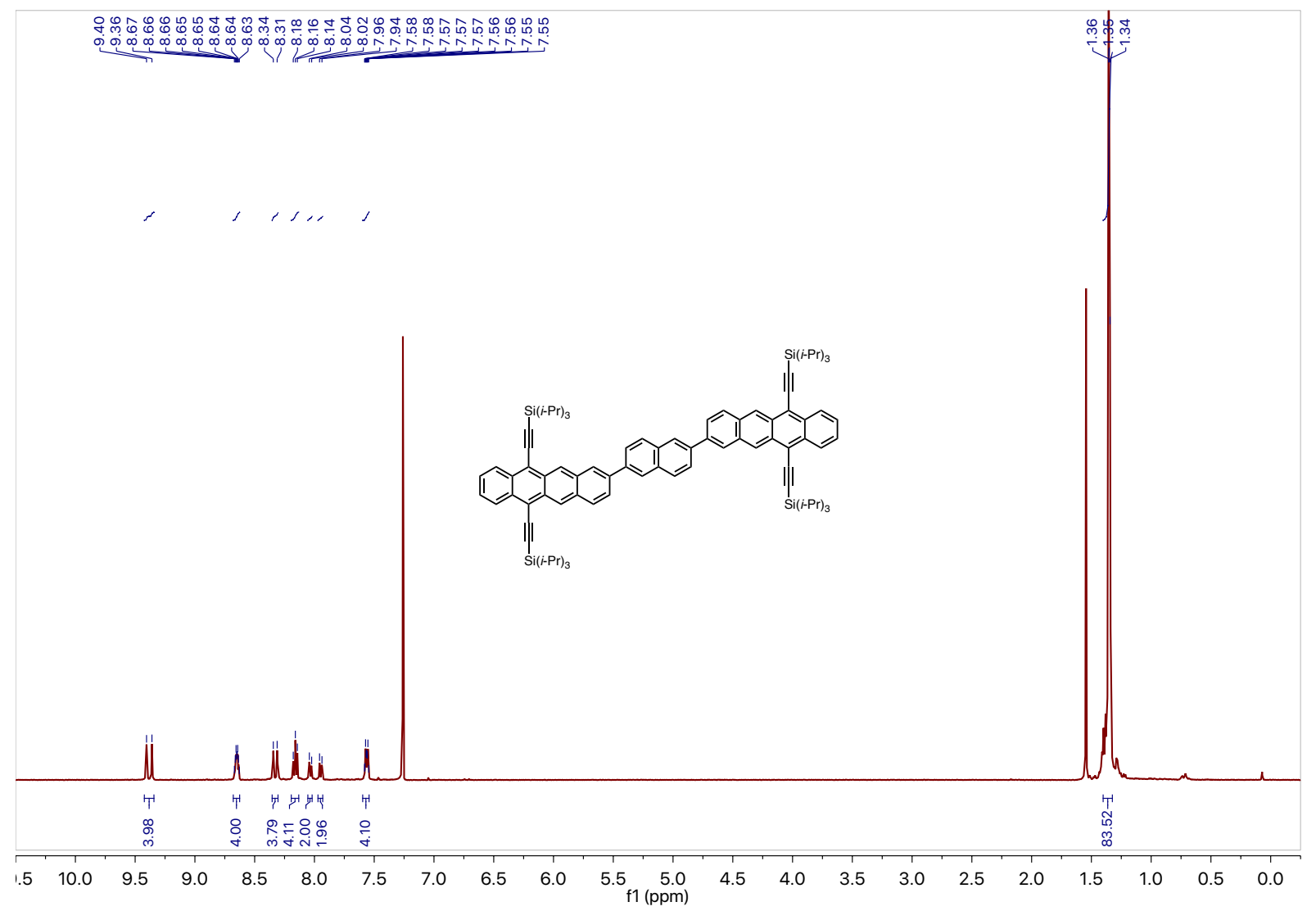




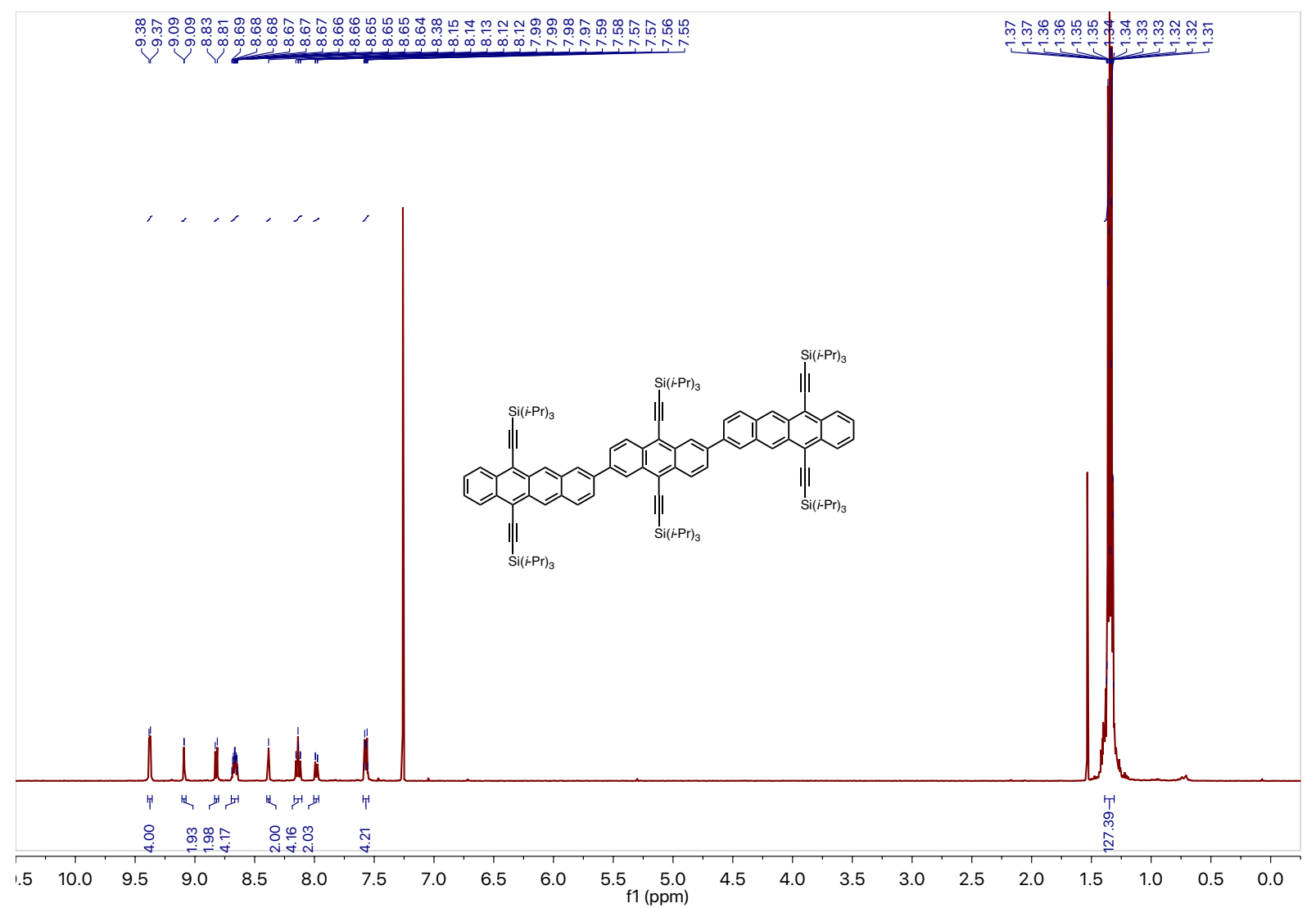




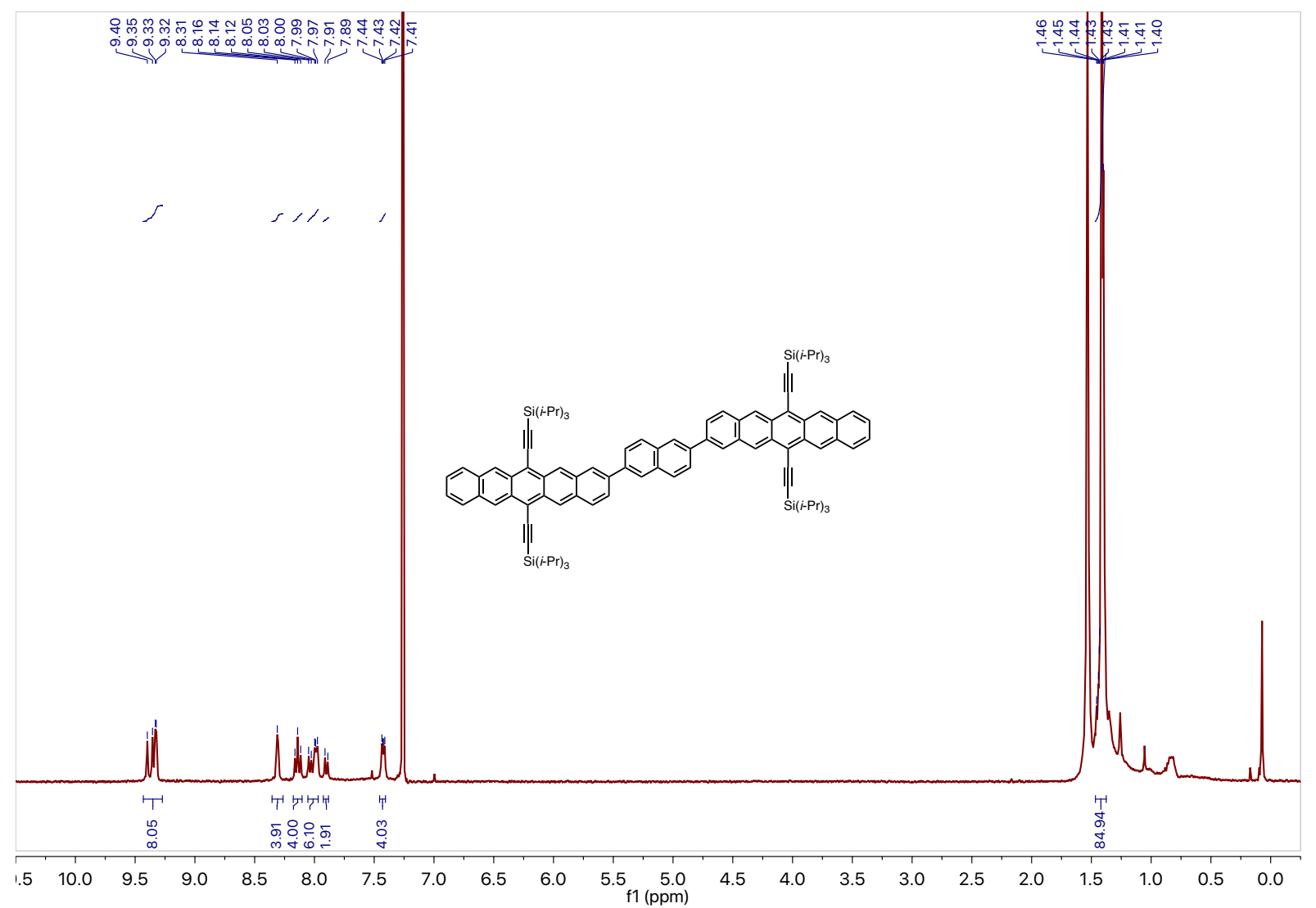




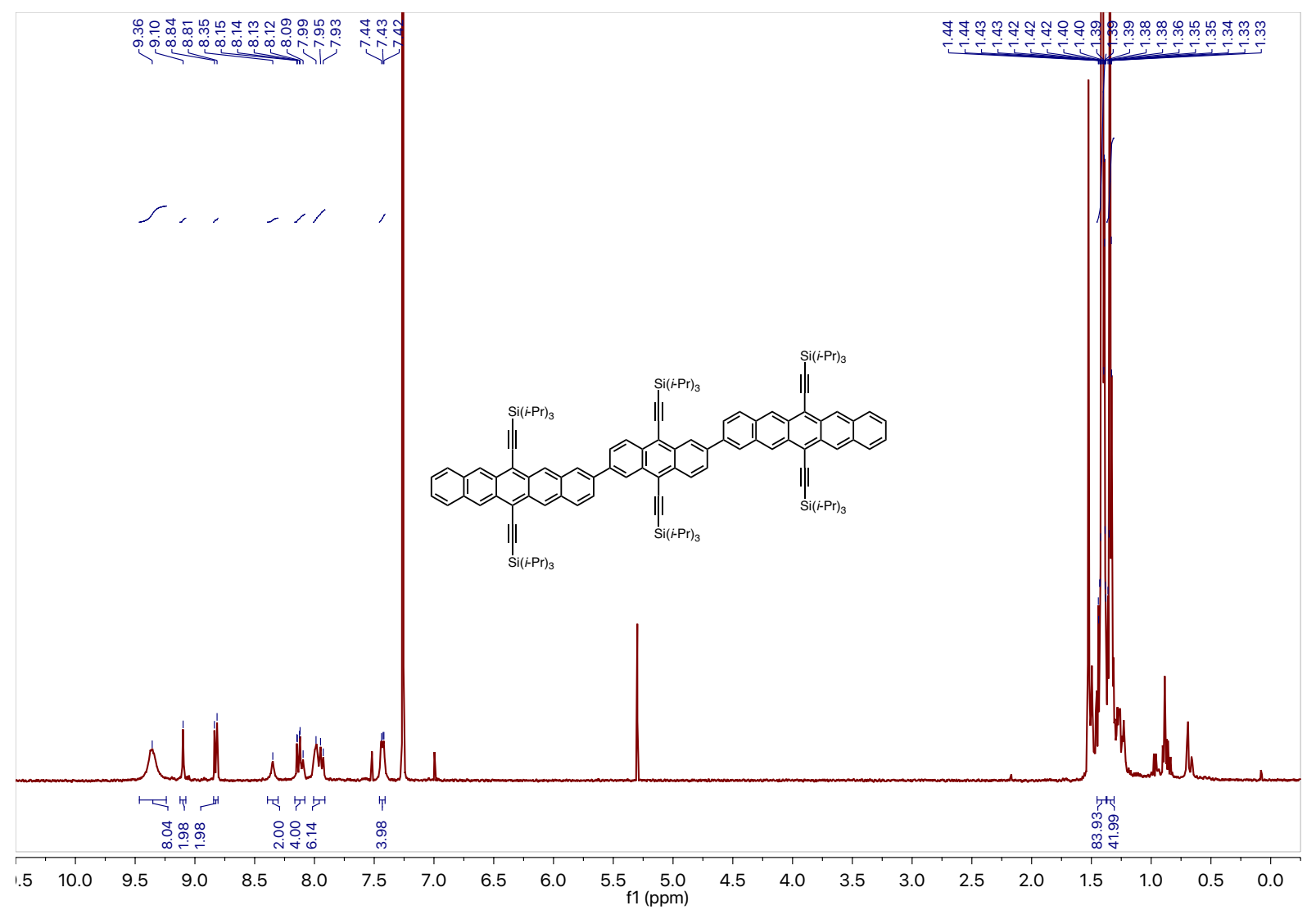




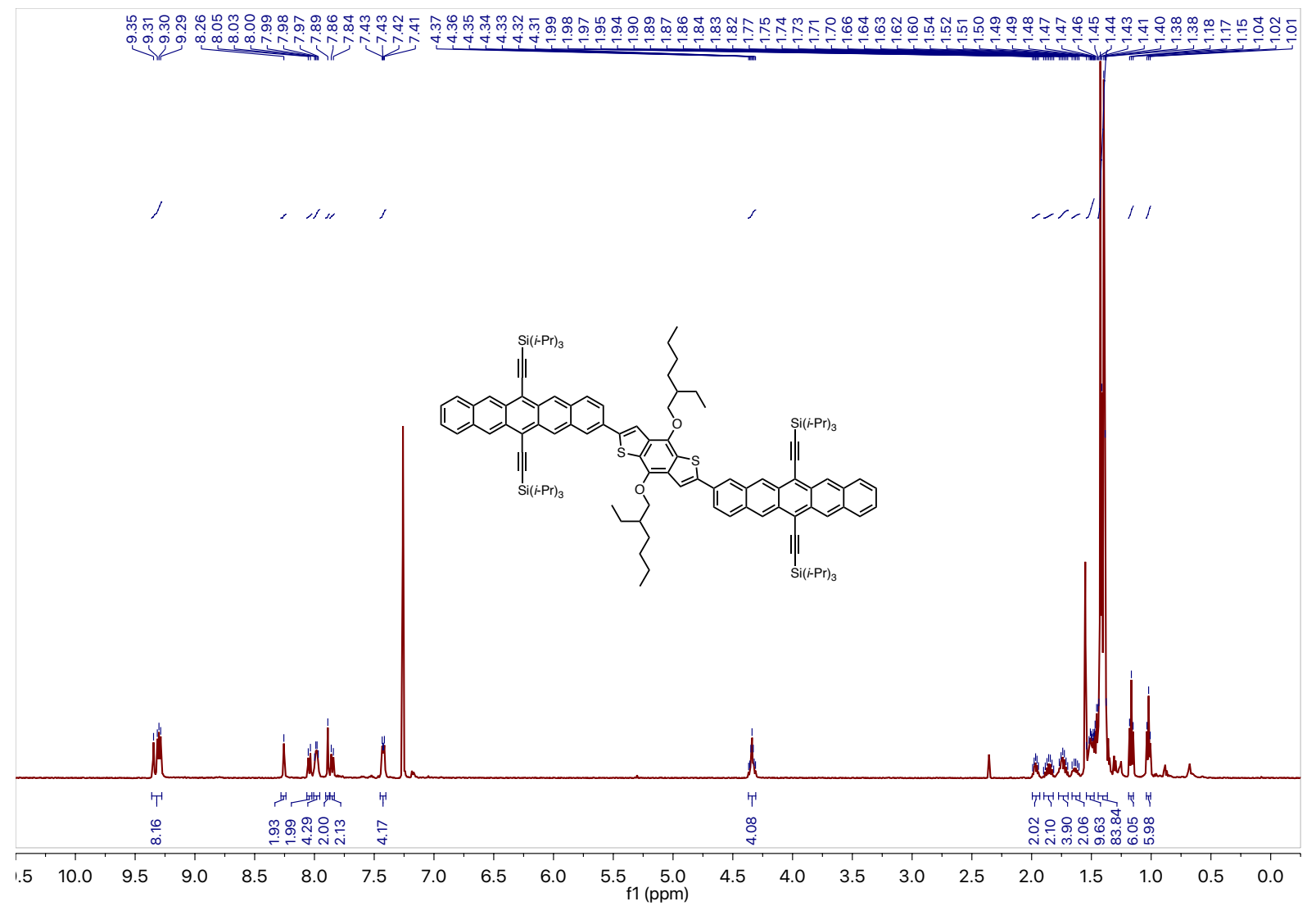




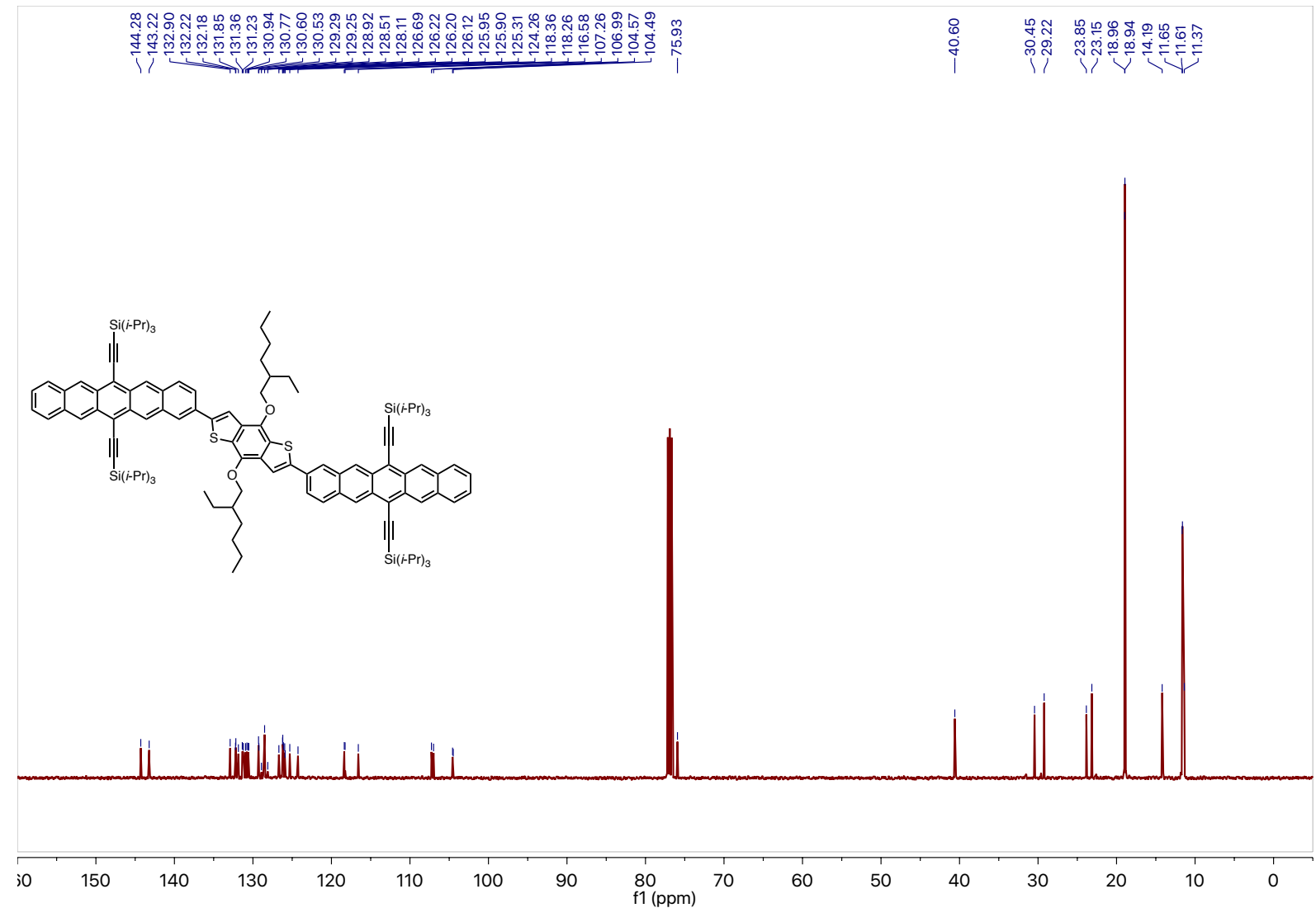




\section{References}

(1) Sanders, S. N.; Kumarasamy, E.; Pun, A. B.; Trinh, M. T.; Choi, B.; Xia, J.; Taffet, E. J.; Low, J. Z.; Miller, J. R.; Roy, X.; et al. Quantitative Intramolecular Singlet Fission in Bipentacenes. J. Am. Chem. Soc. 2015, 137, 8965-8972.

(2) Pun, A. B.; Sanders, S. N.; Sfeir, M. Y.; Campos, L. M.; Congreve, D. N. Annihilator Dimers Enhance Triplet Fusion Upconversion. Chem. Sci. 2019, 10, 3969-3975.

(3) Hou, J.; Chen, H.-Y.; Zhang, S.; Chen, R. I.; Yang, Y.; Wu, Y.; Li, G. Synthesis of a Low Band Gap Polymer and Its Application in Highly Efficient Polymer Solar Cells. J. Am. Chem. Soc. 2009, 131, 15586-15587.

(4) Park, J. H.; Chung, D. S.; Park, J. W.; Ahn, T.; Kong, H.; Jung, Y. K.; Lee, J.; Yi, M. H.; Park, C. E.; Kwon, S. K.; et al. Soluble and Easily Crystallized Anthracene Derivatives: Precursors of Solution-Processable Semiconducting Molecules. Org. Lett. 2007, 9, 2573-2576.

(5) Davis, W. B.; Svec, W. A.; Ratner, M. A.; Wasielewski, M. R. Molecular-Wire Behaviour in p-Phenylenevinylene Oligomers. Nature 1998, 396, 60-63.

(6) Thompson, A. L.; Mart, T. J. Time-Resolved Photoelectron Spectroscopy from First Principles: Excited State Dynamics of Benzene. Faraday Discuss. 2011, 150, 293-311.

(7) Merkel, P. B.; Luo, P.; Dinnocenzo, J. P.; Farid, S. Accurate Oxidation Potentials of Benzene and Biphenyl Derivatives via Electron-Transfer Equilibria and Transient Kinetics. J. Org. Chem 2009, 74, 5163-5173.

(8) Montalti, M.; Credi, A.; Prodi, L.; Gandolfi, M. T. Handbook of Photochemistry; CRC Press, 2006.

(9) Gould, I. R.; Ege, D.; Moser, J. E.; Farid, S. Efficiencies of Photoinduced ElectronTransfer Reactions: Role of the Marcus Inverted Region in Return Electron Transfer within Geminate Radical-Ion Pairs. J. Am. Chem. Soc 1990, 112, 42904301.

(10) Zhu, E.; Ge, G.; Shu, J.; Yi, M.; Bian, L.; Hai, J.; Yu, J.; Liu, Y.; Zhou, J.; Tang, W. Direct Access to 4,8-Functionalized Benzo[1,2-b:4,5-b']Dithiophenes with Deep Low-Lying HOMO Levels and High Mobilities. J. Mater. Chem. A 2014, 2, 13580 13586.

(11) Sanders, S. N.; Kumarasamy, E.; Pun, A. B.; Steigerwald, M. L.; Sfeir, M. Y.; Campos, L. M. Intramolecular Singlet Fission in Oligoacene Heterodimers. Angew. Chemie Int. Ed. 2016, 55, 3373-3377.

(12) Griffith, O. L.; Jones, A. G.; Anthony, J. E.; Lichtenberger, D. L. Intermolecular Effects on the Hole States of Triisopropylsilylethynyl-Substituted Oligoacenes. J. Phys. Chem. C 2010, 114, 13838-13845.

(13) Kumarasamy, E.; Sanders, S. N.; Tayebjee, M. J. Y.; Asadpoordarvish, A.; Hele, T. J. H.; Fuemmeler, E. G.; Pun, A. B.; Yablon, L. M.; Low, J. Z.; Paley, D. W.; et

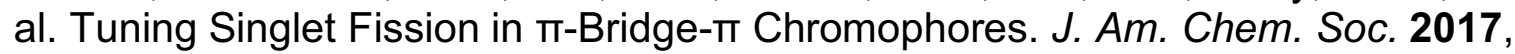
139, 12488-12494.

(14) Alagna, N.; Han, J.; Wollscheid, N.; Luis Perez Lustres, J.; Herz, J.; Hahn, S.; Koser, S.; Paulus, F.; Bunz, U. H. F.; Dreuw, A.; et al. Tailoring Ultrafast Singlet Fission by the Chemical Modification of Phenazinothiadiazoles. J. Am. Chem. 
Soc. 2019, 141, 8834-8845.

(15) Ma, L.; Zhang, K.; Kloc, C.; Sun, H.; Michel-Beyerle, M. E.; Gurzadyan, G. G. Singlet Fission in Rubrene Single Crystal: Direct Observation by Femtosecond Pump-Probe Spectroscopy. Phys. Chem. Chem. Phys. 2012, 14, 8307-8312. 